CORRESPONDENCE

\section{Ultraviolet radiation and cataract}

EDITOR,-Dolin ${ }^{1}$ has recently presented an excellent, balanced review of epidemiological evidence relating to the controversial question of whether there is a link between solar UVB (280-315 $\mathrm{nm}$ ) exposure and cataract. Among other conclusions, he finds that there is limited evidence to suggest the existence of such a link for cortical and posterior subcapsular cataracts but not for nuclear cataract, and goes on to argue the need for further epidemiological studies incorporating very careful assessment of lifetime UVB exposures.

This latter point is of great importance in view of the fact that several past epidemiological studies ${ }^{2-4}$ used annual hours of sunshine as an index of possible exposure. Even disregarding the various personal factors that are discussed by Dolin, sunshine hours are a
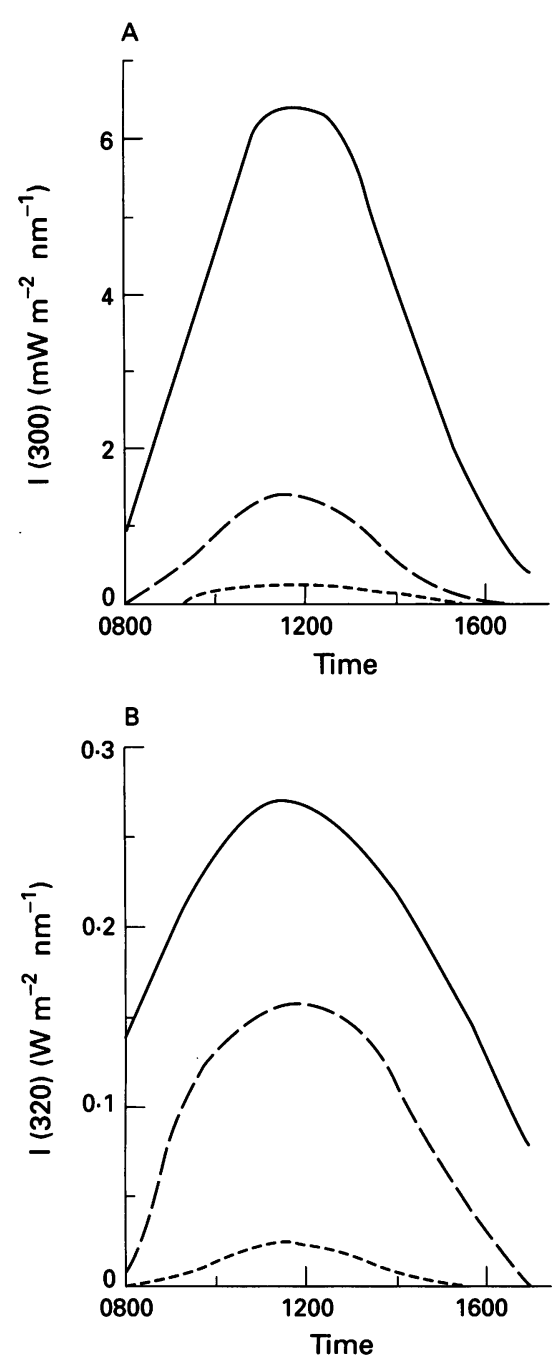

Figure 1 Daily variation in irradiance at the same site in Reading, Berkshire on three cloudless days. - 11 fuly 1990; - - -28 September 1990; ----- 29 November 1990; the minimum solar zenith angles at noon are about 29,54 , and 73 degrees respectively. Wavelength of $(A) 300 \mathrm{~nm},(B) 320 \mathrm{~nm}$. Note the much greater irradiances during the summer months and that the effect of changing solar zenith angle is larger at the shorter wavelength (after (Webb ${ }^{5}$ ). rather poor guide to UVB exposures, since the flux reaching the earth's surface is strongly dependent on solar zenith angle. When the sun is low in the sky (that is, the zenith angle is large), the airpath for absorption and scattering is much longer so that much less UVB reaches the ground. This effect becomes more marked as the wavelength reduces (Fig 1, after Webb ${ }^{5}$ ). Clearly, in the UK, an hour in the midsummer sun around noon is likely to involve much higher levels of exposure than a similar time interval in the late afternoon, or under a midwinter sun. Such effects mean, for example, that in studies of the prevalence of cataract in Himalayan villages, ${ }^{3}$ loss of early or late sunshine through shadowing by the mountain peaks may have little effect on the possible integrated daily UVB exposures. ${ }^{6}$ In fact, when the sun is low in the sky, almost all of the terrestrial UVB is scattered radiation from the sky rather than direct radiation from the sun. ${ }^{7}$ It is also important to note that clouds are a much weaker attenuator of short wavelength than long wavelength radiation, so that UVB levels may remain relatively high even though the sky is cloudy. ${ }^{5}$

Even when the solar angle is allowed for, estimation of ocular exposure levels is, of course, complicated not only by variations in such local and seasonal factors as the weather, altitude, atmospheric aerosol and ozone concentrations, and the albedo of the environment, all of which affect the UVB irradiance, but also by the position of the eyes in the head, head orientation, the wearing of hats and spectacles, and the indoor/outdoor activity patterns of the individual. All this emphasises the need, as stressed by Dolin, ${ }^{1}$ to monitor reliably individual exposures before firm conclusions can be reached on possible UVB associations with cataract or other conditions. This has already been attempted in some studies. ${ }^{8}$ It is sobering to note, however, that calibration, even of sophisticated instrumentation, remains a problem. A recent European cooperative study, in which six groups measured the solar spectral irradiance at the same time at the same location, showed variations by factors as great as two between the irradiances measured by individual instruments. ${ }^{9}$ UMIST, PO Box 88 , Manchester M60

1 Dolin PJ. Ultraviolet radiation and cataract: review of the epidemiological evidence. $\mathrm{Br} \mathscr{f}$ Ophthalmol 1994; 78: 478-82.

2 Taylor HR. The environment and the lens. $B r f$ Ophthalmol 1980; 64: 303-10.

3 Brilliant LB, Grasset NC, Pokhrel RP, Kolstad A Lepkowski JM, Brilliant GE, et al. Association among cataract prevalence, sunshine hours, and altitude in the Himalayas. Am $\mathcal{f}$ Epidemiol 1983; 118: $250-64$.

4 Hiller R, Giacometti L, Yuen K. Sunlight and cataract: an epidemiological investigation. $A m^{\mathcal{F}}$ Epidemiol 1977; 105: 450-9.

5 Webb AR. Solar ultraviolet radiation in southeas England: the case for spectral measurements. Photochem Photobiol 1991; 54: 789-94.

6 Sliney DH. Physical factors in cataractogenesis ambient ultraviolet radiation and temperature. Invest Ophthalmol Vis Sci 1986; 27: 781-90.

7 Blumthaler M, Ambach W. Spectral measurements of global and diffuse solar ultraviolet-B radiant exposure and ozone variations. Photochem Photobiol 1991; 54: 429-32.

8 Rosenthal FS, Phoon C, Bakalain AE, Taylor HR. The ocular dose of ultraviolet radiation to outdoor workers. Invest Ophthalmol Vis $S$ 1988; 29: 649-56.

9 Gardiner BG, Kirsch PJ. European intercomparison of ultraviolet spectrometers, Panorama, Greece, 3-12 July 1991, Air Pollution Research Report 38. Brussels: Commission of the European Communities, Directorate General for Science Research and Development, 1992.

\section{Reply}

EDITOR,-Charman has highlighted the problem of using hours of sunshine at place of residence as a measure of ocular exposure to UVB. This further supports the need in epidemiological studies for careful assessment of ocular UVB exposure at the individual level. Charman raises two issues that warrant further examination.

First, the figure he presents of UVB irradiance at different times of day in Berkshire shows that UVB irradiance varies with time of day within the one location. There is a strong peak centred on solar noon with irradiance dramatically falling away on either side of noon. This variation adds to the complexity of exposure assessment. Consider two individuals living and working in the same geographical location. One works outdoors and is exposed to sunlight for most of the day, but spends the lunch hour resting indoors. Although long hours are spent outdoors, this worker is indoors when UVB irradiance is at a peak. The other is an indoor office worker who only spends the lunch hour outdoors. In this scenario, the indoor worker's UVB exposure may in fact be similar to the outdoor worker's exposure.

The second issue is the Himalayan study undertaken by Brilliant and colleagues. ${ }^{1}$ This study is continually referred to in the ophthalmic community as casting doubt on an association between UV exposure and cataract. On numerous occasions I have heard persons say that while the Chesapeake Bay watermen's study and Beaver dam studies support an association, ${ }^{2} 3$ the Himalayan study casts doubt on an association. In the Himalayan study the prevalence of cataract in different locations in Nepal was examined in relation to hours of sunlight and altitude at each location. Hence this was a geographical correlation study, not an analytical study. From the epidemiological viewpoint, the Himalayan study was innovative, of sound design, and well conducted. At that time (1983) correlation studies were state of the art in cataract aetiology research. However, in reviewing epidemiological evidence, for UV radiation or any other risk factor, most weight is usually given to the findings of analytical studies, particularly those in which exposure was assessed at the individual levels, while the findings of geographical correlation studies tend to play a supporting role. In assessing the evidence one looks to see if the correlation studies provide support to the findings of analytical studies. The Himalayan study, like most correlation studies, should be viewed in this context.

$$
\begin{array}{r}
\text { PAUL DOLIN } \\
\text { Institute of Ophthalmology, } \\
\text { Bath Street, } \\
\text { London ECIV } 9 E L
\end{array}
$$

1 Brilliant LB, Grasset NC, Pokhrel RP, Kolstad A Lepkowski JM, Brilliant GE, et al. Association among cataract prevalence, sunlight hours, and altitude in the Himalayas. Am $\mathcal{F}$ Epidemiol 1983 118: $250-64$

2 Taylor HR, West SK, Rosenthal FS, Munoz B, Newland HS, Abbey $\mathrm{H}$, et al. Effect of ultraviolet radiation on cataract formation. $N$ Engl f Med 1988; 319: 1429-33.

3 Cruickshanks KJ, Klein BE, Klein R. Ultraviole light exposure and lens opacities: the Beaver dam eye study. Am $¥$ Public Health 1992; 82: dam eye 